\title{
Factors Affecting Health Seeking Behavior and Health Services in Pakistan
}

\author{
Khudija Mushtaq*, Muhammad Hussain, Muhammad Afzal, Syed Amir Gilani
}

Lahore School of Nursing, The University of Lahore, Punjab, Pakistan.

\begin{abstract}
Health seeking practices and well-being management has been considered and the determinants are divided into physical, financial, social and political environments. Health knowledge as well as the activities is the key elements that ensure high quality of health. The audit found clear practices that pursue differences in sexual orientation, social conditions, infection occurrences and family economic conditions. In this way, an evidence-based approach must be planned by establishing an understanding of the way happiness practices and social insurance are used, and giving enough credibility to all determinants. By focusing on the benefits (network) factors caused by environment, financial variables, training levels, social beliefs and the human service framework itself, it is feasible to improve the requirements for the use of solid behavior and physical medical services. Men are considered to be the main head of a family. Men's instruction level is considered higher than women because men are dominant in our society.
\end{abstract}

Keywords: Financial, Communicable, Disease, Factors, Health seeking behavior, Health services, Determinants, Decision making.

\section{INTRODUCTION}

The actions related to health behavior are to promote good health and prevent from risk of diseases but sickness behavior can be positive and negative to real health difficulties. The pursuit of healthy behavior and the use of medical services depend on the association of welfare frameworks. The well-being framework involves not only the structure that provides social insurance, but also the different components that make up the framework as a whole. These are monetary conditions, family frameworks, socially encouraged people, social forces, ecological conditions, political frameworks, and so on. They often affect the way in which medical services are sought. With regard to the social insurance framework, in almost all founding countries, public and private well-being coexists, complementing or conflicting [1]. Various studies have shown that the use of public or private, formal or casual human service framework models depends to a large extent on factors, for example, age and gender, women's self-sufficiency, urban or rural living space, economic status, disease severity, access to physical foundations, various welfare professional organization and units, etc. [2].

Since 1990, maternal mortality has declined worldwide by $50 \%$, but this decline has been uneven among and within countries. According to WHO estimates in 2015, 830 women died each day from preventable causes associated with pregnancy and childbirth, and 3.1 million newborns died in their first month of life. Almost $99 \%$ of all maternal deaths occurred in low-income and middle-income countries (LMICs) [3]. More than half of the global neonatal deaths in 2009, occurred in five countries including Pakistan (India, Nigeria, China and the Democratic Republic of Congo). Pakistan remains the 11th worst performing country in the

*Address correspondence to this author at the Lahore School of Nursing, The University of Lahore, Punjab, Pakistan.

E-mail: khudija79@gmail.com world on this indicator [4].

WHO guidelines, in 2016, increased the recommended number of contacts between the mother and healthcare providers at time points that may facilitate assessment of well-being and provision of interventions from four to eight antenatal care (ANC) appointments along with skilled attendance at birth, to reduce maternal and neonatal mortality (deaths in 0-27 days per 1000 live births). Yet, worldwide, even this minimum uptake is achieved by only two-thirds of pregnant women [5]. Community-based interventions such as home visiting and counseling can help to reduce neonatal mortality in LMICs [6]. However, availability of ANC services does not assure uptake, and an understanding of health-seeking behavior during pregnancy is critical to ensure effective ANC uptake [7].

In Pakistan, the average ANC coverage is $37 \%$ and skilled attendance at birth $52 \%$, but ANC coverage ranges from $29.8 \%$ to $85.2 \%$ among different socioeconomic groups [8], influenced by the supply of services and demand for them [9].

Pakistan's Lady Health Worker (LHW) program initiated in 1994 aimed to improve maternal and child health outcomes by deploying locally recruited female health workers to provide community-based primary healthcare. The program has helped to reduce infant mortality due to higher immunization uptake [3], but with limited improvements in ANC uptake [8] with implications for neonatal mortality.

Women in Pakistan experience social vulnerability and disempowerment, with poor nutrition, limited education, early marriage and high fertility rates, and the LHW programme was designed to address these factors that adversely affect women's health-seeking behavior $[5,10]$. 


\section{OBJECTIVES}

To find out the factors affecting health seeking behavior and health services in Pakistan.

\section{METHODOLOGY}

We discussed about different factors that affect health seeking behavior and reviewed different articles from Google Scholar, PubMed and Research Gate. The articles were discussed from $2001-2017$ for review.

\section{HEALTH CARE SYSTEM IN PAKISTAN}

There is a reasonable division of the personnel service framework in Pakistan; the public part of state subsidies and the private sector work independently to gain benefits. Some health indicators are improving, for example, vaccination and family scheduling. Lack of education, the low status of women and inadequate water and sanitation have completely eased the trend of movement of health indicators for $65 \%$ of the country's population. Social barriers hinder the pursuit of healthy openness in the current successful therapeutic management. At the network level, the "Ms. Welfare Workers" program has earned worldwide prestige for its grassroots inclusiveness and support for a solid system that is considered essential for the office at the tertiary level. However, limited working hours and remote areas of the framework cannot change the image. Subsequently, good practices and tendencies were moderated, especially at national civilian gatherings [11].

\section{THE HEALTH POSITION OF FEMALES AND KIDS}

The low social position of females leads to unacceptable and preventable maternal births and may be the highest mortality rate in South Asia. Undoubtedly, this seriously affects the well-being of women and their young people, especially confidence. In countries in the region, sick women report fewer opportunities to seek human services than men. Kids are being suppressed in the household and need to seek authorization from the head of the household or the male in the family to get recovery considerations. Maternal and child medical problems are extremely normal, but due to different reasons within the welfare framework, these issues have not been resolved. The lack of qualified female welfare workers limits women's access to appropriate considerations to a large extent. In Pakistan, more than $80 \%$ of births are delivered by untrained midwife or traditional birthing specialists. The suitability of the authorities is more subtle than the social standards and customer needs with clear sexual orientation [12]. In any case, despite the differences in the countries of the region, women in Pakistan have consistently visited health care providers (any framework), while men visit 5 times a year. Despite the problems of regenerative medicine, due to residential and sexual harassment, general deficiencies, grief and nervousness, an important reason for increasing the rate of lawyers may be long-term medical problems. Studies have shown that women's weights of various cardiovascular hazard variables are more prominent than men's weights, which confirms the total of appointments to rehabilitation institutions. Among young people under the age of 5, upper respiratory tract and gastrointestinal diseases (about 6 times a year) are the most common [13].

In Pakistan, the number of normal contacts with human service providers exceeds 54 years per year, four times a year. This visit even exceeded the number of visits in the United States. This reality may be attributed to the severity of the disease in urban and rural areas of Pakistan (an irresistible and non-transmissible disease). Diseases associated with need and underdevelopment are mainly found in rural areas, such as inadequate diet, intestinal peristalsis, intestinal loosening, disease, hepatitis, tuberculosis and other serious repellent respiratory diseases. In addition, the medical problems of women are still uncertain, which has prompted women to seek medical services from a variety of formal and leisure professional institutions. Again, most of the urban population faces diseases such as diabetes, high blood pressure, malignant growth, joint inflammation and stroke. The whole process makes the huge burden of natural pollution and street traffic damage more chaotic [14].

\section{THE NON-COMMUNICABLE DISEASE BURDEN}

High blood pressure as well as diabetes is two central points in the growing burden of disease. In Pakistan, not all of these diseases are documented, and they are unusually obvious. Due to the predominance of cardiovascular infections, high blood pressure, diabetes, smoking and dyslipidemia become burden of diseases in Pakistan. In contrast, women in Pakistan have a greater clinical cardiovascular risk factor than men. Endless bronchitis is another cause of death. In the age group of 65 years and older, the prevalence of rural women is as high as $14 \%$, while the prevalence of rural men is as high as $6 \%$. In urban areas, the proportion of two people is $9 \%$. Along these lines of thought, one might think that this may be the weight of a non-metastatic disease, and for this reason, such a large number of therapeutic drugs have been recorded [15].

\section{PUBLIC VERSUS PRIVATE HEALTH CARE UTILI- ZATION}

In the creation of a country, the underutilization of the general welfare management department is actually inclusive. The NHS shows a comparative pattern in which the total number of government experts accounts for $21 \%$ of the total number of care. Residents in rural areas depend to a large extent on the extent to which the government calms staff and parents. Ladies should rely on the limits of social versatility. Despite this, several government experts are interviewed each year compared to other treatment providers who visit four or two times a year. Similarly, provincial-level regional government experts use even lower speeds than urban areas [16]. First, 
there are no experts in many important human service environments. Second, regarding female patients, the open sector does not employ many female experts. Many times, due to the lack of qualified faculty, the nature of medications and care, patients need to visit many experts to treat similar diseases. The patient's own health-related habits, especially drug compliance, are another factor to consider. Even so, all visits did not portray visits and courtesy. This does not mean that everyone is participating in social insurance [17]. The nature of drug management given by the general public and private population has long been regrettable. When the country is created, everything is finished, and the higher use rate of the private sector homeopathic health office can be attributed to simple access, shorter waiting times, longer open hours or adaptability, and the supply of people and medicines. Is the epidemic mentality and privacy high? Despite this, the responsiveness and order of welfare specialist organizations in private medical clinics in the country are still flawed. In any case, rationality is still a problem. NHS research shows that as many as $65 \%$ of the population consults private experts. Women with low financial positions account for $30 \%$ of all considerations, while women with high financial positions account for $68 \%$ of all considerations [11].

\section{HEALTH AND ECONOMICS OF PAKISTAN}

In South Asia, about $80 \%$ of the total amount paid on health care per annum is depends on amount of household out of pocket cost. Out of pocket finance in Pakistan is $76 \%$. This factor also determines the ability of individuals or families to meet their human service needs. Undoubtedly, this cost has greatly hindered the search for suitable medical services in Pakistan. This unpredictability is reflected in the pursuit of good behavior, including the use of home remedies and the use of drugs obtained from neighbors or drugs obtained from drug stores for self-medication. In the National Health Service, there is no difference in the use of welfare management agencies in terms of financial status. The irrelevant comparison of urban and rural populations in the use of welfare management institutions does not reflect the way these two populations enjoy similar welfare status. Regardless of how the interest of the provincial poor is expanding, they do need quality management and should be based on treatment. Separation from the closest restorative facility has been identified as a major obstacle to use, especially in provincial areas. In the National Health Services (NHS), the results of the survey indicate that at least $5 \%$ of people have received treatment from Hakim, homeopathic and conviction experts. This description seems to be rare because traditional ideas are often intertwined with the particularities of the disease itself and with different ecological, monetary and social factors. In countries, the most intimate and accessible providers are temporary experts, mainly because they have made minimal efforts and therefore need to provide advice to them. Family financial problems clearly limit decision making and open the door to seeking happiness [18].

As of recently, the Ministry of Health's Punjab government has established a nationwide system of treatment organizations, pharmacies, welfare centers, obstetrics and gynecology, routine therapists and private clinics. Despite this, there are still differences in the delivery methods and real areas of welfare offices in urban and provincial areas. Therefore, a few people have more access to medical services than others. Some networks require public offices that are primarily used by the poor, which may affect an individual's quest for stability. The problem of poor circulation of sanitation facilities has affected the medicinal tendencies of some networks, which has hindered the use of welfare agencies [18].

\section{DECISION MAKING FACTOR}

Most of the family leaders are male. Although, the absolute number of women encountered is actually equal to that of men. Men have a basic obligation to determine a women's social insurance needs, because men are the head of the family and the main leader of different individuals in the family, especially those who seek medical care when they are unwell. Men are more educated than women. Although, women are the basic guardians of relatives and hardly respect their subtleties, they deny their basic health mindfulness and medical services. Despite age, gender and marital status, family leader's occupation, salary, family size, information and guidance also determine how their health services are used and seek solid behavior $[11,19]$.

\section{CULTURAL VALUES}

Any public social estimate, especially social estimates of the national territory, is accustomed to directing individuals to family therapy, self-care and customary treatment. At home, the guidance of the old lady has been considered and valued. It delays the treatment options for women, but at the same time delays the treatment options for adolescent diseases, thus affecting the pursuit of social insurance. About some patients go to the treatment room for less real or some real reasons, while the rest are indeed extreme. Moreover, it affects the identification of mindfulness and disease, gender, treatment office arrangements and implementation. The proportion of women in open-end medical clinics is higher than that of men who go to private emergency rooms for treatment. The contrast of sexual orientation will also affect the prosperity of Pakistani women. Most respondents have a source of salary, but no matter where they have a low-paying person, they are not suitable for purchasing drugs, and occasionally need cash for treatment [20].

\section{FINANCIAL DIVERGENCE}

Intrinsic cultural currency differences and lack of cash management in the absence of government-managed savings measures make people in distress even more at risk, especially when paying for repair costs and choosing a source of 
treatment. Low livelihoods make it impossible for the network to take advantage of the benefits in the welfare office, and the choice of unreasonable choices when manual services are needed will also have a negative impact on benefits. In South Asia, in many countries, the network is found to pay $80 \%$ of the out-of-pocket payments to the medical management department each year. The currency-related limit for the use of social insurance offices in Pakistan is equal to $76 \%$ of the payment for out-of-pocket expenses. Undoubtedly, high expenditures have seriously hindered the use of social insurance in Pakistan. The cost of visiting experts and receiving treatment is not only an obstacle, but the cost of transportation (the cost of reaching the Social Insurance Office) also has a deterrent effect, and the absolute cost is enormous. Therefore, the economic situation of the family leads them to choose medical institutions to seek treatment. Simple access to the primary health care (PHC) is considered a basic network right. Most members believe that the PHC office area is good for them, but most people are disappointed with the plan to restore the office. More than $75 \%$ said that the most recent private pharmacies have every prescription they need. For example, in Pakistan's low- and middle-wage countries, travel time and costs, because there is no transportation and no foundation, consolidate the use of medical institutions and expand the expenditures of restorative institutions [21].

\section{GEOGRAPHICAL LOCATION FACTOR}

The convenience of transportation, the size of the social insurance office and the opportunity to go to the medical services office will definitely affect the use and utilization of the Human Services Office by the Human Services Foundation. This geographic access from the nearest medical foundation to the treatment office is seen as a barrier for patients and clients and is seen as a primary need for the use of rehabilitation facilities in provincial areas. In this way, geographic access is parallel to different angles, such as transportation and travel rates [19, 22], (Fig. 1).

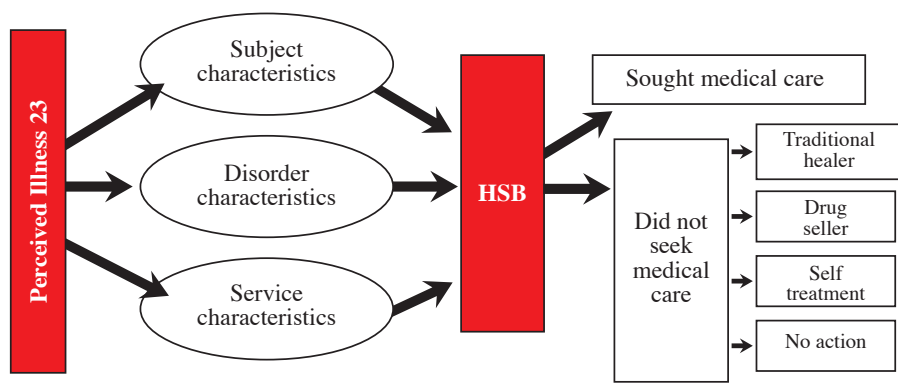

Fig. (1). Health Services Behavior and Illness.

\section{CONCLUSION}

It is concluded that due to lack of concentration, inadequate medicine and low level of teaching, the PHC office is not used properly. The concept of patient complaints and the length of the disease describe the use, source and type of human services. By hampering people's demands from geography, financial variables, training levels, social beliefs, and the medical services framework itself, and through the boundaries of these essentials through human service programs, and people can improve their pursuit of behavior and basic life. Make good use of social insurance. Data and realities about drug service behavior are necessary to identify opportunities, successfully manage and streamline implementation

\section{CONFLICT OF INTEREST}

Declared none.

\section{ACKNOWLEDGEMENTS}

\section{Declared none.}

\section{REFERENCES}

[1] Chakraborty M, Ghosh S. Common childhood morbidity and treatment seeking behaviour in an Indian megacity: A Case Study of North Kolkata. J Indian Anthrop Soc 2019; 54: 30-50.

[2] Latunji OO, Akinyemi OO. Factors influencing health-seeking behaviour among civil servants in Ibadan, Nigeria. Ann Ib Postgrad Med 2018; 16(1): 52-60.

[3] World Health Organization. Fact sheet. 2015; Available at: https://apps.who.int/iris/bitstream/handle/10665/112318/WHO_RHR_14.06_eng.pdf

[4] Oestergaard MZ, Inoue M, Yoshida S, et al. Neonatal mortality levels for 193 countries in 2009 with trends since 1990: A systematic analysis of progress, projections, and priorities. PLoS Med 2011; 8(8): e1001080.

DOI: 10.1371 journal.pmed.1001080

[5] Ahmad R, Zhu NJ, Lebcir RM, Atun R. How the health-seeking behaviour of pregnant women affects neonatal outcomes: Findings of system dynamics modelling in Pakistan. BMJ Global Health 2019; 4(2): e001242.

DOI: 10.1136/bmjgh-2018-001242

[6] Lassi ZS, Middleton PF, Bhutta ZA, Crowther C. Strategies for improving health care seeking for maternal and newborn illnesses in low- and middle-income countries: A systematic review and meta-analysis. Global Health Action 2016; 9(1): Article: 31408 . DOI: 10.3402/gha.v9.31408

[7] Persson LA, Nga NT, Målqvist M, et al. Effect of facilitation of local maternal-and-newborn stakeholder groups on neonatal mortality: Cluster-randomized controlled trial. PLoS Med 2013; 10(5): e1001445. DOI: 10.1371/journal.pmed.1001445

[8] Kearns AD, Caglia JM, Hoope-Bender PT, Langer A. Antenatal and postnatal care: A review of innovative models for improving availability, accessibility, acceptability and quality 
of services in low-resource settings. BJOG 2016; 123(4): 540-8. DOI: $10.1111 / 1471-0528.13818$

[9] Scammell K, Noble DJ, Rasanathan K. A landscape analysis of universal health coverage for mothers and children in South Asia. BMJ Global Health 2016; 1(1): e000017.

DOI: 10.1136/bmjgh-2015-000017

[10] Rwashana AS, Nakubulwa S, Nakakeeto-Kijjambu M, Adam T. Advancing the application of systems thinking in health: Understanding the dynamics of neonatal mortality in Uganda. Health Res Policy Syst 2014; 12(1): 36.

DOI: $10.1186 / 1478-4505-12-36$

[11] Hussain R, Rashidian A, Hafeez A, Mirzaee N. Factors influencing healthcare seeking behaviour at primary healthcare level in Pakistan. J Ayub Med Coll Abbottabad 2019; 31(2): 201.

[12] (a) Ogunlesi TA, Olanrewaju DM. Socio-demographic factors and appropriate health care-seeking behavior for childhood illnesses. J Trop Pediatr 2010; 56(6): 379-85;

DOI: $10.1093 /$ tropej/fmq009

(b) De Zoysa I, Carson D, Feachem R, Kirkwood B, Lindsay-Smith E, Loewenson R. Perceptions of childhood dirrhoea and its treatment in rural Zimbabwe. Soc Sci Med 1984; 19(7): 727-34; DOI: 10.1016/0277-9536(84)90245-4

(c) Asenso-Okyere WK, Anum A, Osei-Akoto I, Adukonu A. Cost recovery in Ghana: Are there any changes in health care seeking behaviour? Health Policy Plan 1998; 13(2): 181-8. DOI: 10.1093/heapol/13.2.181

[13] Poortaghi S, Raiesifar A, Bozorgzad P, Golzari SEJ, Parvizy S, Rafii F. Evolutionary concept analysis of health seeking behavior in nursing: A systematic review. BMC Health Services Res 2015; 15(1): 523.

DOI: $10.1186 / \mathrm{s} 12913-015-1181-9$

[14] Dey S. Impacts of female literacy rate on infant mortality rate in bangladesh: An econometric exercise. Millennium Univ J
2017; 2(1): 44-53.

Mushtaq et al.

[15] Ha NTH, Berman P, Larsen U. Household utilization and expenditure on private and public health services in Vietnam. Health Policy Plann 2002; 17(1): 61-70.

DOI: $10.1093 /$ heapol/17.1.61

[16] Katung PY. Socio-economic factors responsible for poor utilisation of the primary health care services in a rural community in Nigeria. Nigerian J Med: J Nat Assoc Resid Doc Nigeria 2001; 10(1): 28-9.

[17] Kiwanuka SN, Ekirapa EK, Peterson S, et al. Access to and utilisation of health services for the poor in Uganda: A systematic review of available evidence.Trans R Soc Trop Med Hyg 2008; 102(11): 1067-74. DOI: 10.1016/j.trstmh.2008.04.023

[18] Ergete S, Sorsa S, Loha E, Asnake S. Trend of malaria cases in Hana and Keyafer health centers, South Omo Zone, Southern Ethiopia. Ethiop J Health Sci 2018; 28(3): 277-86.

DOI: $10.4314 /$ ejhs.v28i3.5

[19] Whicher D, Rosengren K, Siddiqi S, Simpson L, Eds. The Future of Health Services Research: Advancing Health Systems Research and Practice in the United States. Washington (DC): National Academies Press (US) 2018.

[20] Peltzer K, Promtussananon S. HEALTH care-seeking behaviour for child illnesses among ruralmothers in South Africa: A pilot study. Health SA Gesondheid 2003; 8(2): 3-13. DOI: $10.4102 /$ hsag.v6i2.62

[21] Zaidi S, Bigdeli M, Aleem N, Rashidian A. Access to essential medicines in Pakistan: Policy and health systems research concerns. PloS One 2013; 8(5): e63515.

DOI: 10.1371 journal.pone.0063515

[22] Ippolito M, Chary A, Daniel M, Barnoya J, Monroe A, Eakin M. Expectations of health care quality among rural Maya villagers in Sololá Department, Guatemala: A qualitative analysis. Int J Equity Health 2017; 16: 51.

DOI: 10.1186/s12939-017-0547-5 